\title{
Health efficacy of electrically operated automated massage on muscle properties, peripheral circulation, and physio-psychological variables: a narrative review
}

\author{
Ayan Paul', Juliana Usman', Mohd Yazed Ahmad', Mohafez Hamidreza' ${ }^{1}$, Hadizadeh Maryam², Zhi Chao Ong ${ }^{3}$, \\ Khairunnisa Hasikin ${ }^{1}$ and Khin Wee Lai ${ }^{1 *}$ (1)
}

${ }^{*}$ Correspondence:

lai.khinwee@um.edu.my

${ }^{1}$ Department of Biomedical Engineering, Universiti

Malaya, 50603 Kuala Lumpur, Malaysia

Full list of author information is available at the end of the article

\begin{abstract}
Manual massage, commonly used by healthy individuals for well-being, is an ancient practice requiring the intervention of a trained and experienced physiotherapist. On the other hand, automated massage is carried out by machines or modalities without or with minimal control of a human operator. In the present review, we provide a literature analysis to gather the effects of automated massage on muscle properties, peripheral circulation and psychophysiological variables as reported through psychometric and neurophysiological evaluations of each modality ranging from massage beds and whole-body vibrations to robotic massage. A computerized search was performed in Google Scholar, PubMed, and ResearchGate using selected key search terms, and the relevant data were extracted. The findings of this review indicate that for vibration massage, whole-body vibration exposure with relatively lower frequency and magnitude can be safely and effectively used to induce improvements in peripheral circulation. As for massage chair and mechanical bed massage, while most studies report on positive changes, the lack of strong clinical evidence renders these findings largely inconclusive. As for robotic massage, we discuss whether technological advances and collaborative robots might reconcile active and passive modes of action control during a massage and offer new massage perspectives through a stochastic sensorimotor user experience. This transition faculty, from one mode of control to the other, might definitely represent an innovative conceptual approach in terms of human-machine interactions.
\end{abstract}

Keywords: Automated massage, Muscle properties, Peripheral circulation, Robotic massage

\section{Introduction}

Time spent in both work and recreational activities by modern day people have drastically shifted toward longer durations spent in sedentary positions and such habits, over the last decades, have had detrimental effect on our lives. The effects are nonetheless furthered and aggravated through overuse of computers and smartphone

(c) The Author(s), 2021. Open Access This article is licensed under a Creative Commons Attribution 4.0 International License, which permits use, sharing, adaptation, distribution and reproduction in any medium or format, as long as you give appropriate credit to the original author(s) and the source, provide a link to the Creative Commons licence, and indicate if changes were made. The images or other third party material in this article are included in the article's Creative Commons licence, unless indicated otherwise in a credit line to the material. If material is not included in the article's Creative Commons licence and your intended use is not permitted by statutory regulation or exceeds the permitted use, you will need to obtain permission directly from the copyright holder. To view a copy of this licence, visit http:// creativecommons.org/licenses/by/4.0/. 
alike, which consequently lead toward postural deformity, neck and shoulder pain as evidenced by research, and when prolonged and recurred, these habits gradually degrade our overall health. Fortunately, massage techniques had been in practice in many cultures throughout human history as a means to prevent such disorders. However, while generally accepted and appreciated, manual massage has largely been considered a companion treatment rather than a therapeutic intervention per se. Massage targets soft tissue such as muscles, tendons and facias. Conventionally, manually applied massage is imparted on these aforementioned structures as the masseuse or physiotherapist performs several maneuvers including effleurage, kneading, static or slide pressures, but also light and deep pressures. They are likely to involve biomechanical, physiological, neurological and psychological mechanisms, although these empirical attributions are not always confirmed by scientific data [54]. Delivering manual massage requires a trained physiotherapist/individual and such interventions are difficult to scale up given that only one individual can tend to a single patient at a time. Furthermore, while the benefits of massage in literature is extensively demonstrated for individuals with or without motor disorders, manual massage interventions still remain rather time-consuming and expensive. Additionally, some researchers have indicated that effectiveness of manually administered massage may degrade as the physiotherapist tend to exhaust with successive interventions [43].

Earlier studies on the efficacy of massage have encompassed several physiological and physical parameters such as heart rate variability [7], blood pressure $[1,16]$ as well as cognitive abilities such as psychological record, mental operation [4, 5, 24, 39], and neural activity [8]. The outcomes of these studies have been indicated that massage therapy could be beneficial in relieving not only physical stress such as chronic lower back pain and headache $[6,51]$, but also psychological stress induced from anxiety $[9$, 35] and depression [13]. However, decades of independent attempts have not been able to unearth the underlying mechanism of massage therapy. Nevertheless, the massage therapy research has been suggestive of two possible mechanisms of effect. The first one describes about activation of parasympathetic nervous system via massage, which in turn lowers blood pressure, heart rate and muscle fatigue and subsequently promotes muscle oxygenation $[11,12,36]$. The other theory suggests that the effect of massage is linked to activation of the sympathetic nervous system.

Commercially, a great deal of electrically operated massage devices is available at consumer market. These devices include automated massage chair, mechanical massage beds, vibration mattresses, pneumatic-air massage, robotic massage modalities, and so on. The present paper provides a synthesis of the experimental evidence of automated massage on the human body as per reported in preceding studies. Additionally, we look into robotic massage solutions and their prospective development in assisting classical massage with more interactive and proactive modes to deliver optimal massage experience to end user. The literature review was conducted using three search engines: Google Scholar, PubMed, and ResearchGate, and restricted to only papers on English language. The search involved sets of inclusion and exclusion criteria. A total of 79 articles including the keywords: "automated massage," "vibration massage," "mechanical massage," and "robotic massage" were reviewed, and finally 45 articles were retained. 


\section{Effects of muscle properties}

Two studies investigated on the effect of mechanical bed massage on lower back muscle fatigue, strength, and recovery. In one study by Zhong et al. [52], the researchers induced muscle fatigue through reverse sit ups in prone position followed by mechanical bed massage and evaluated back muscle endurance immediately, and $24 \mathrm{~h}$ after the intervention. The sample for this study comprised entirely of athletes. In another study by Do-Kim et al. [21], trunk extension (TE) was used as an index for back muscle fatigue. In addition to TE, the group also recorded EMG signals to analyze the strength of erector spinae muscles. However, Do-Kim et al. [21] had incorporated heating to the mechanical bed massage intervention to examine the combined effect. Zhong et al. [52] reported no statistically significant difference in back muscle extension (BME) between massage and control group. The study noted the slower rate of decline in BME in massage group, which they associated with increased blood flow and elimination of metabolites, but the evidence was not conclusive. On the other hand, Do-Kim et al. reported a significant improvement in TE and EMG signal after combined application of massage with heating as an indicator of improved flexibility and strength in back muscles.

The potential for vibration-based massage therapy to aid recovery from exerciseinduced muscle stiffness has also been studied. Imtiyaz et al. [19] and Pournot et al. [44], in two separate studies, investigated the effect of vibro-massage in treating stiffness of the biceps brachii muscle generated from weighted loading. Pournot et al. massaged the subject's biceps $5 \mathrm{~min}$ after exercise and $5 \mathrm{~min}$ after recovery period. They used the one arm as control/passive arm and evaluated the shear elastic modulus (SEM) of the other arm after massage. Their study lacked to observe any positive impact of vibration on SEM, and therefore, on muscle stiffness. Furthermore, Imityaz et al. compared the effect of vibration to manual massage and reported increased rate of recovery in groups receiving vibration massage as indicated by lowered level of blood serum LDH (lactate dehydronase). However, the study also reported absence of any significant difference between massage group and vibration group on ROM (range of motion) and level of CK (creatine kinase). In another study by Anna et al. [65], the effect of lower limb vibration on cyclist is documented. In this study, the authors applied vibration for $60 \mathrm{~min}$ after exercise, and reported a gradual decrease in blood lactate level as well as significant difference in other biochemical markers (IL-6, Mb, MMP-2) in experimental groups after intervention. Both Imtiyaz et al. and Anna et al. had varied time points in collection of blood samples ranging from 1 to $72 \mathrm{~h}$ after intervention.

Hiraiwa et al. [18] explored the possibility of robotic massage to treat masseter muscle stiffness in a controlled clinical study. The study population constituted patients suffering from either unilateral or bilateral myofascial pain stemming from masseter muscle stiffness. In this controlled study, the treatment duration ranged from 4 to 12 weeks and authors reported significant reduction in muscle stiffness in the treatment group. Only one study by Durkin et al. [9] involved conducting massage through mechanically designed chair on a car seat. In this study, the authors separately evaluated different massage system integrated to the car seat and found no statistically significant difference.

The Waseda Asahi Oral-Rehabilitation Robot 1 (WASO-1), developed by the Waseda University and Asahi Roentgen Company, aimed at recovery of temporomandibular disorders. The authors approach to unilateral and bilateral temporomandibular disorder 
was targeted to a specific population, highly technical and very expensive. Other studies on investigating the robotic massage effects on masseter and temporal muscles had varying degrees of pressure exerted, which ranged from $100 \mathrm{~g}$ to $1.5 \mathrm{~kg}$ per square area [2, 3, $20,23,46,60]$. The most effective outcome was derived at approx. $800 \mathrm{~g}$ on small facial muscles. The authors further reported that the robotic massage decreased muscle pain and promoted functional motor recovery in patients. Another study by Luo and Chang [30] showed that patients had improved muscle activity after undergoing multi-finger robotic massage. However, the validity of these experimental results remains questionable due to the small sample sizes and complex study designs. Despite the autonomy of these robotic devices and lack of intervention by the physiotherapist, the robotic massages still do not allow for individualization of massage. The robots were designed to follow respective preprogrammed massage commands and did not incorporate a pain threshold for applied pressure considering patient morphology. Instead, like manual massage techniques, the patients had to assume a passive position when receiving massage [55](Table 1).

\section{Effects on peripheral circulation}

A summary characterizing the interventional protocol of different massage modalities on blood circulation is given in Table 2. The larger segment of these studies involve vibrational massage focused on whole-body vibration (WBV). In addition, the electrically operated chair and air-cuff-based massage has also been reported (Table 3).

Variability in terms of exposure session and duration to WBV is stark in the reported studies. Several studies had multiple bouts within the same session. Intra-session variation in exposure from WBV ranged up to $15 \mathrm{~min}$ [47]. While some studies were relatively short term, the duration for long-term intervention ranged from 2 weeks [34] to 12 weeks [32]. In these longitudinal studies, there were up to three intervention session each week of the study period. Differences with regard to vibrational intensity for the WBV interventions ranged from 26 to $44 \mathrm{~Hz}$ with a median exposure of $\leq 30 \mathrm{~Hz}$. All but one study was randomized controlled and, in that study, the exact location of vibrational massage has not been reported. In addition to measuring blood flow, Menendez et al. [33] and Sonza et al. [47] reported on the skin temperature measurements at both baseline and post-intervention. In both cases, an infrared thermography-based temperature measurement was taken on the lower extremity. While Menendez et al. [33] reported on positive changes to side-altering vibration massage, the effect of vertical synchronized WBV according to the other studies, have no significant changes to circulation. However, Mitchel et al. [34] did not report on vertically synchronized vibration. Sonza et al. [47] and Menendez et al. [33] reported on significant alterations in peripheral circulation at vibrational stimulus between 25 and $30 \mathrm{~Hz}$ compared to lower intensities. However, Manimmanakorn et. al. and Mitchel et al.[32, 34] did not observe any significant improvement in terms of long-term intervention with vibrational massage. There are several methodical limitations observed in these studies. Vibrational apparatus for all studies either imparted side-altering or vertical vibration. Given that intensity of the vibrational stimulus in side-altering vibration can change the impact of WBV due to the variability in foot positioning or distance between feet on the vibrational platform, the lack of reporting on these details in almost all studies create some ambiguity 


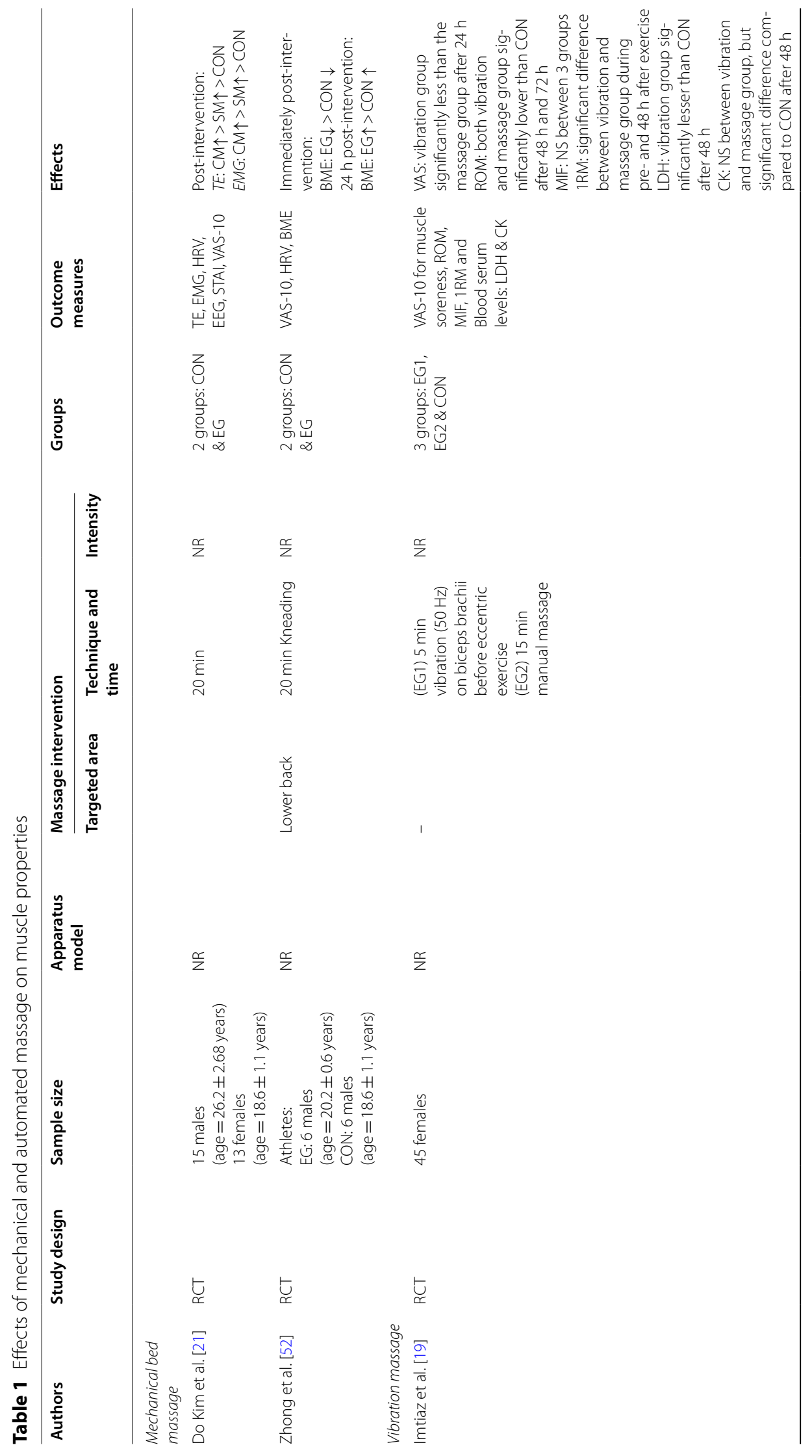




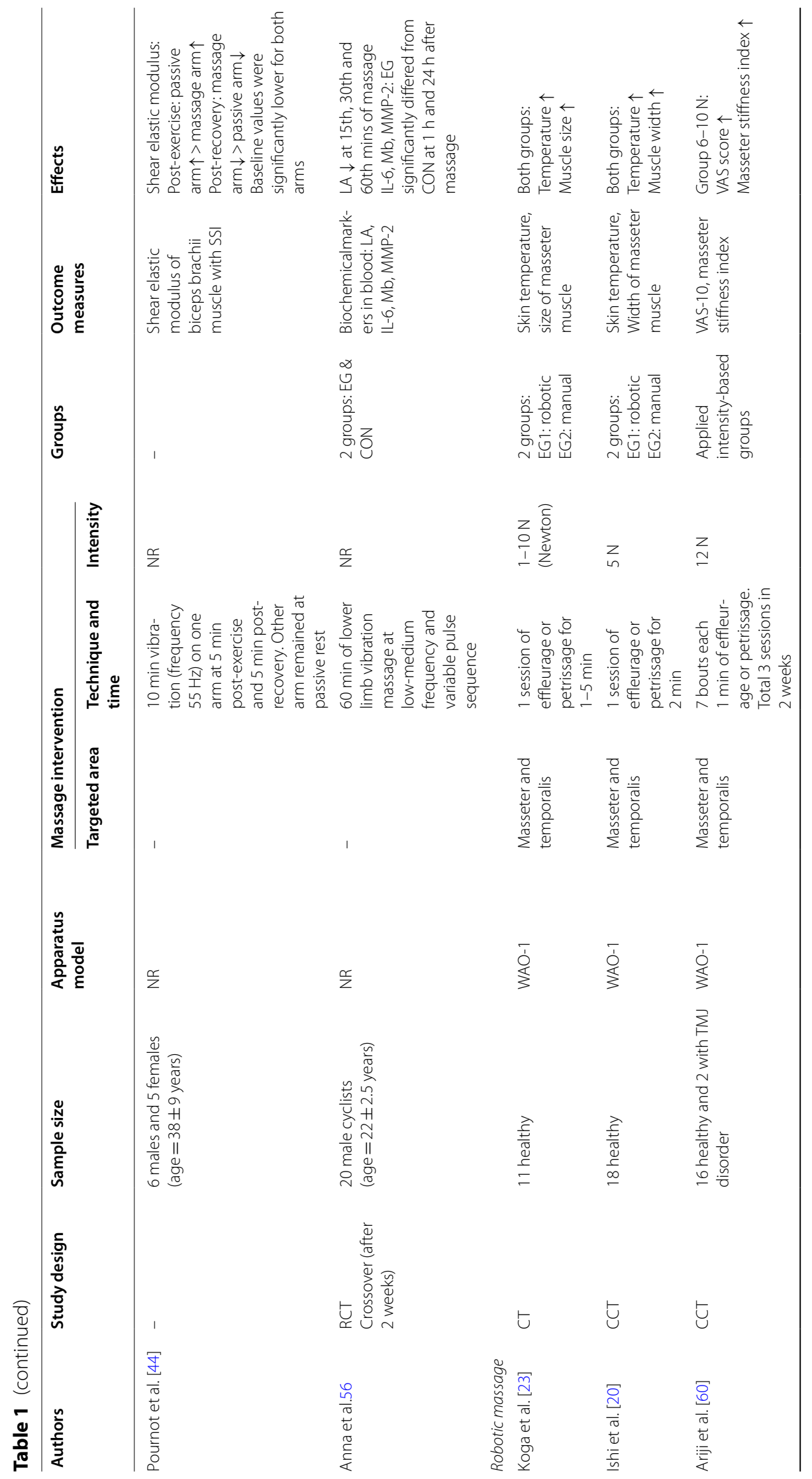




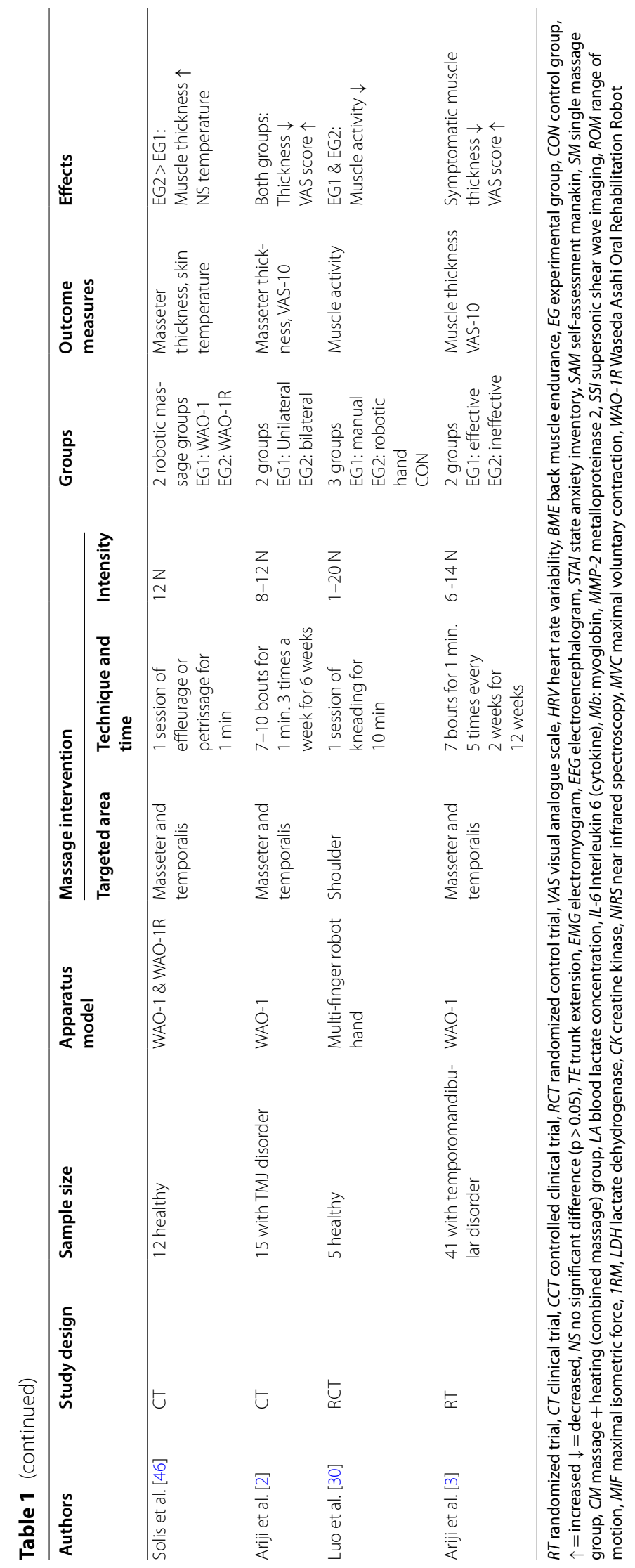




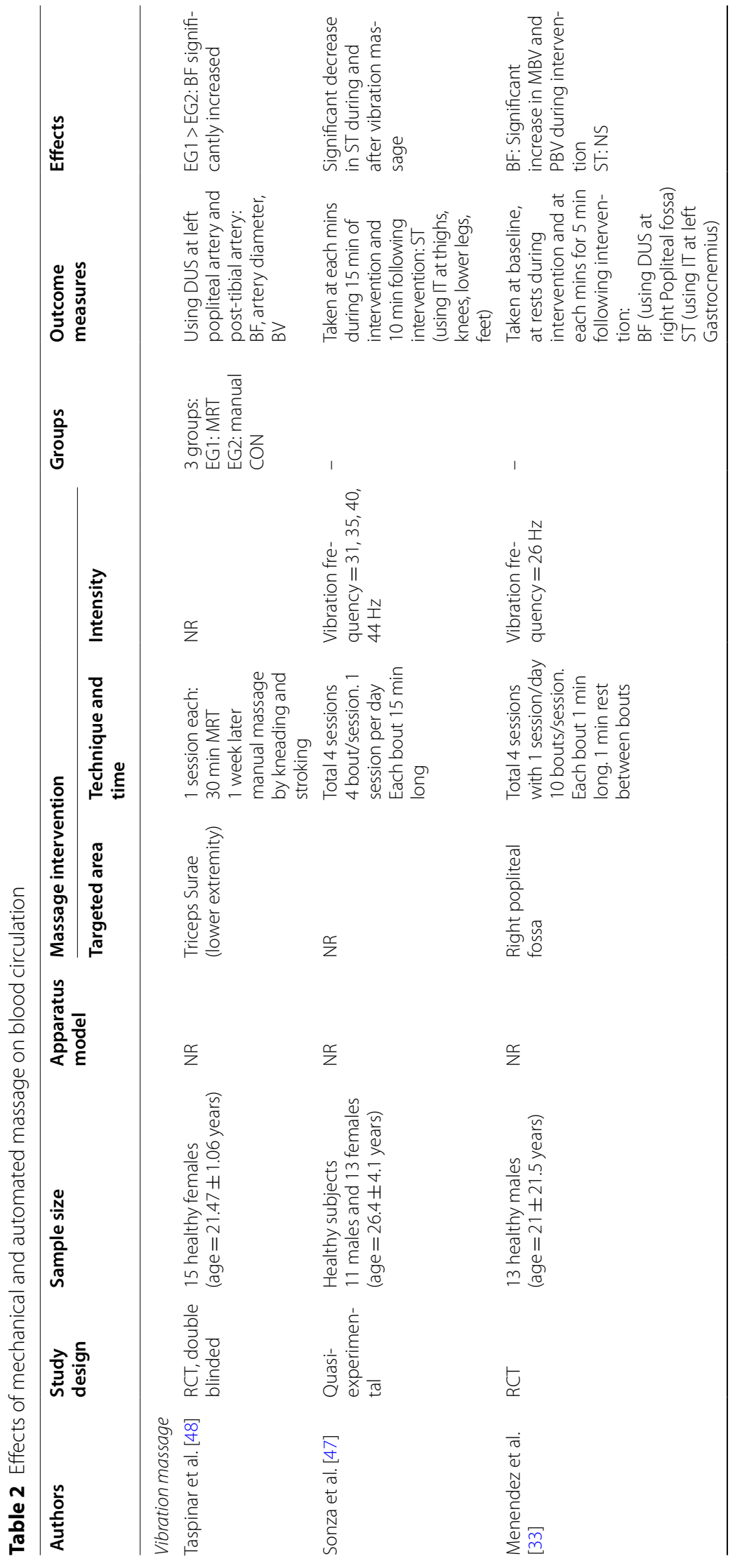




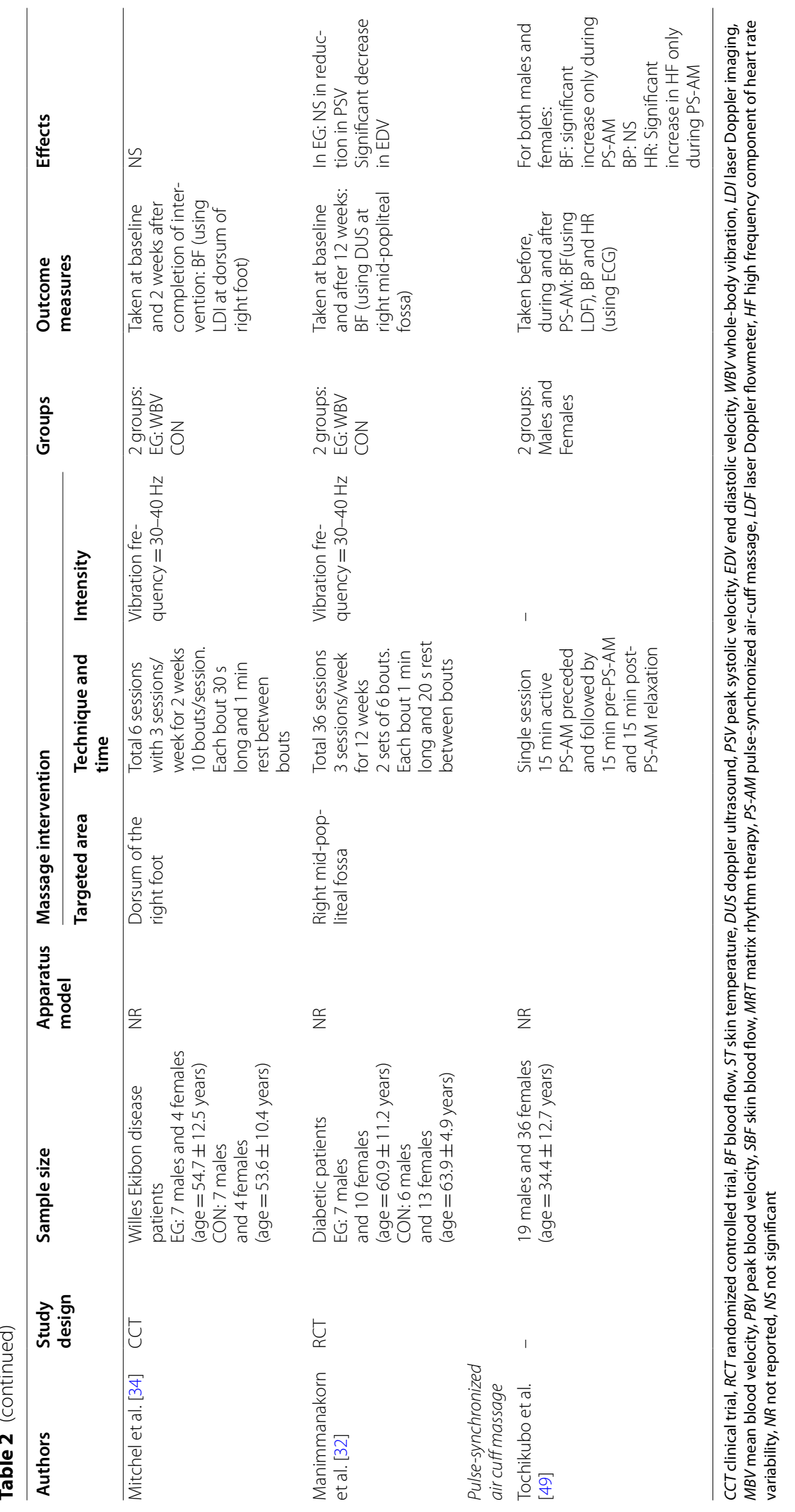




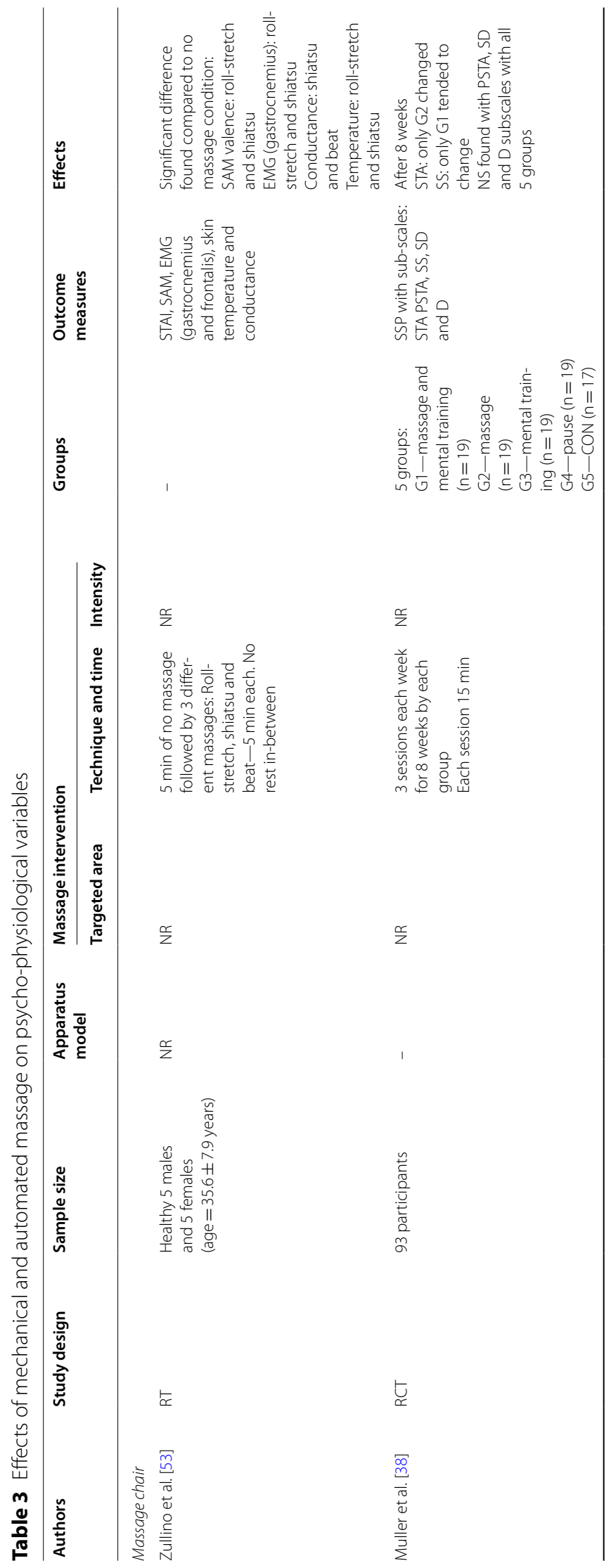




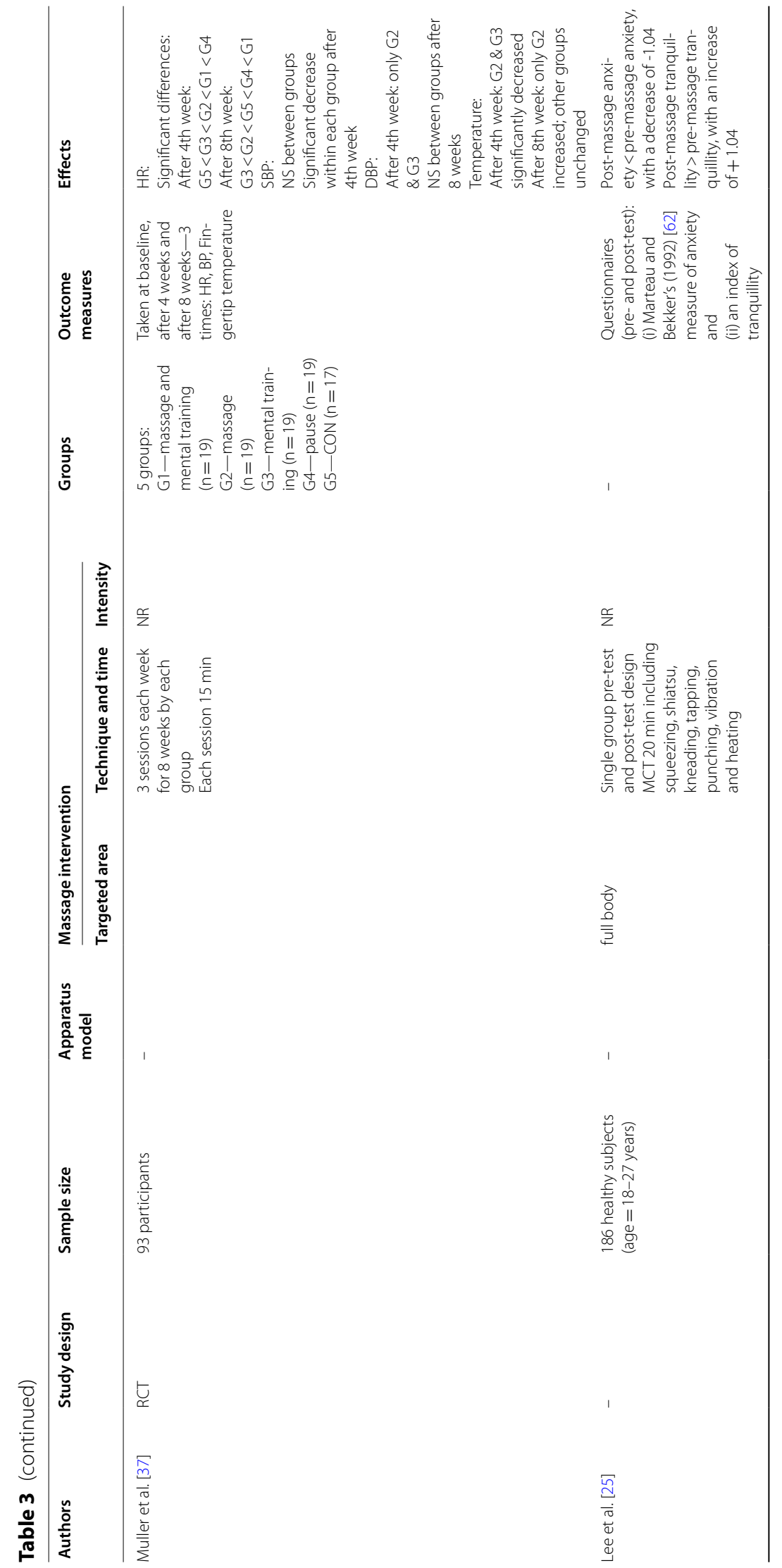




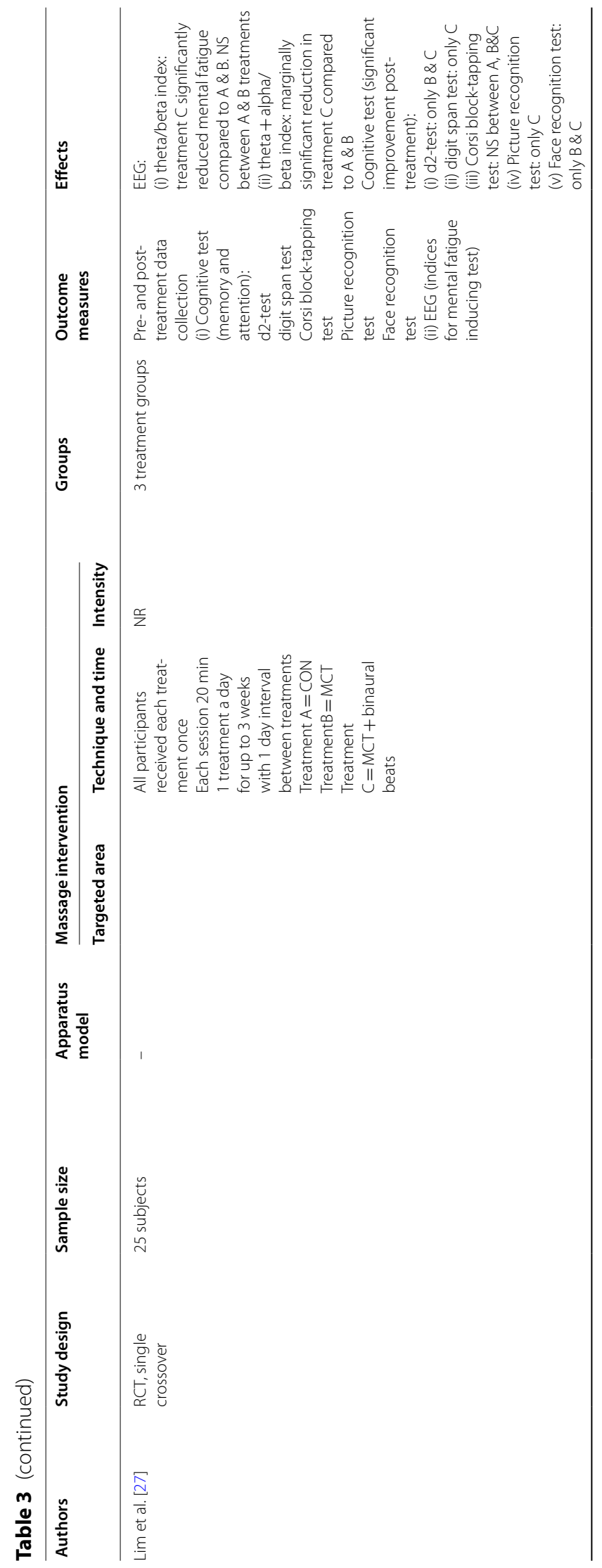




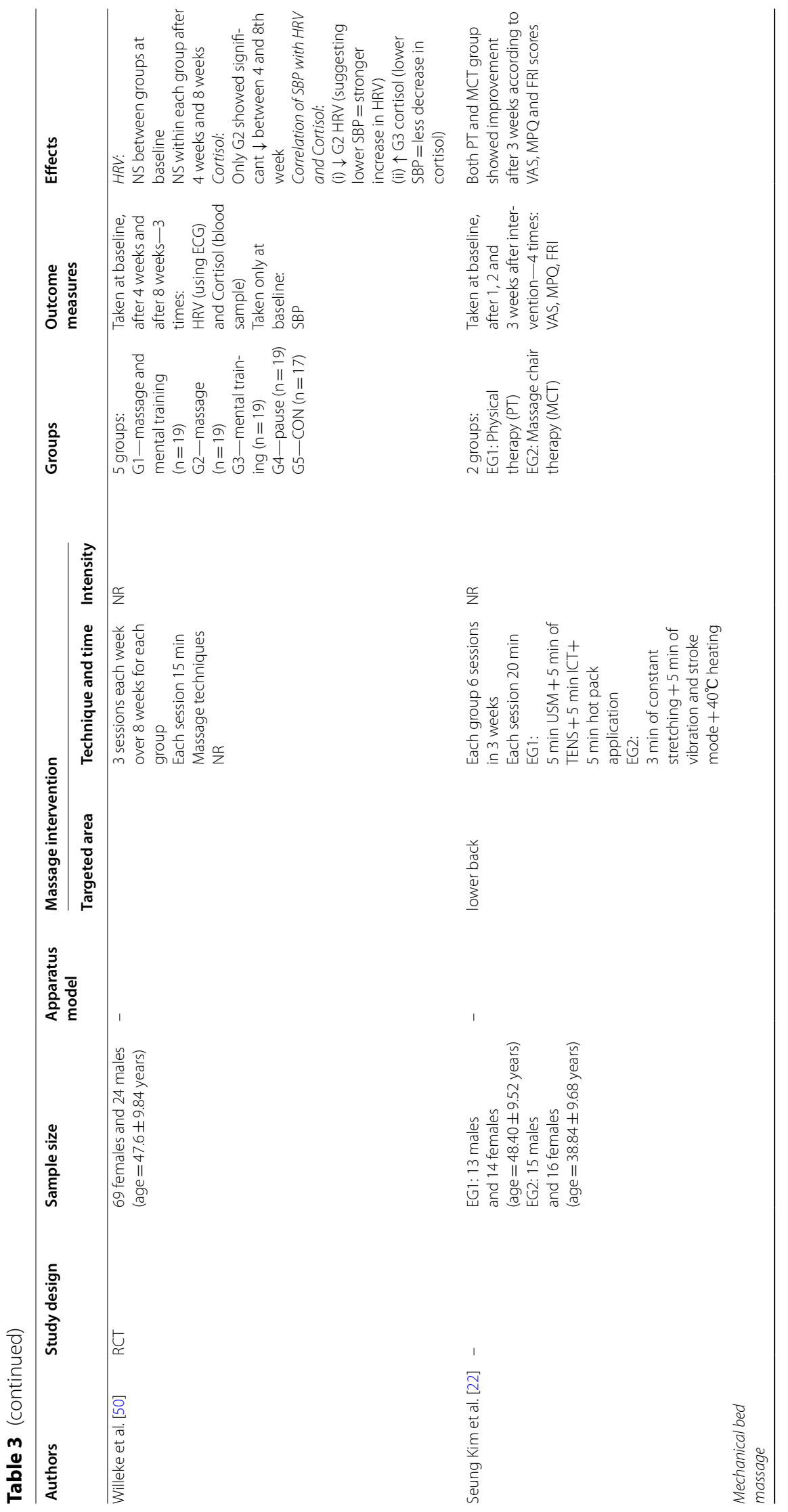




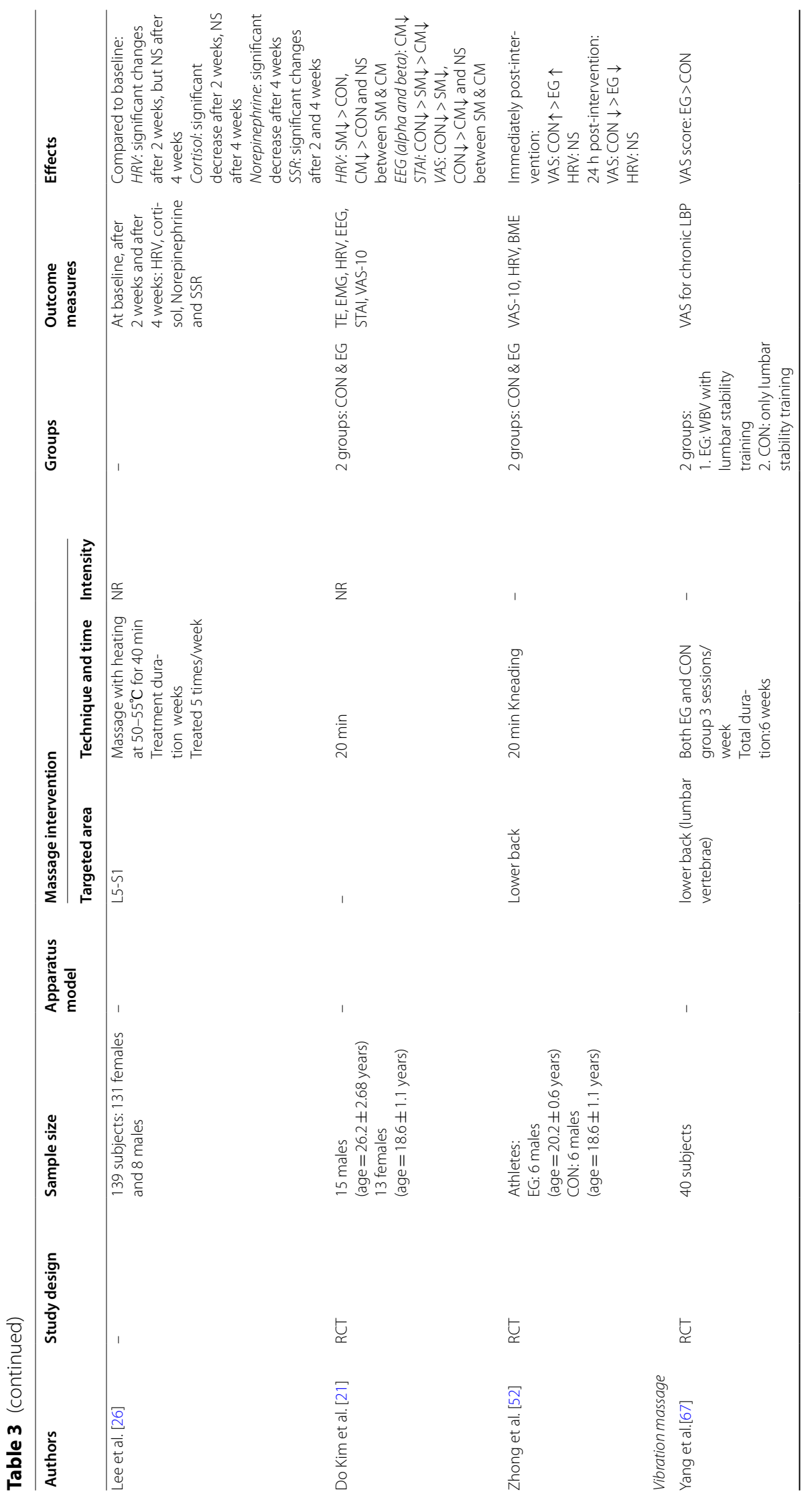




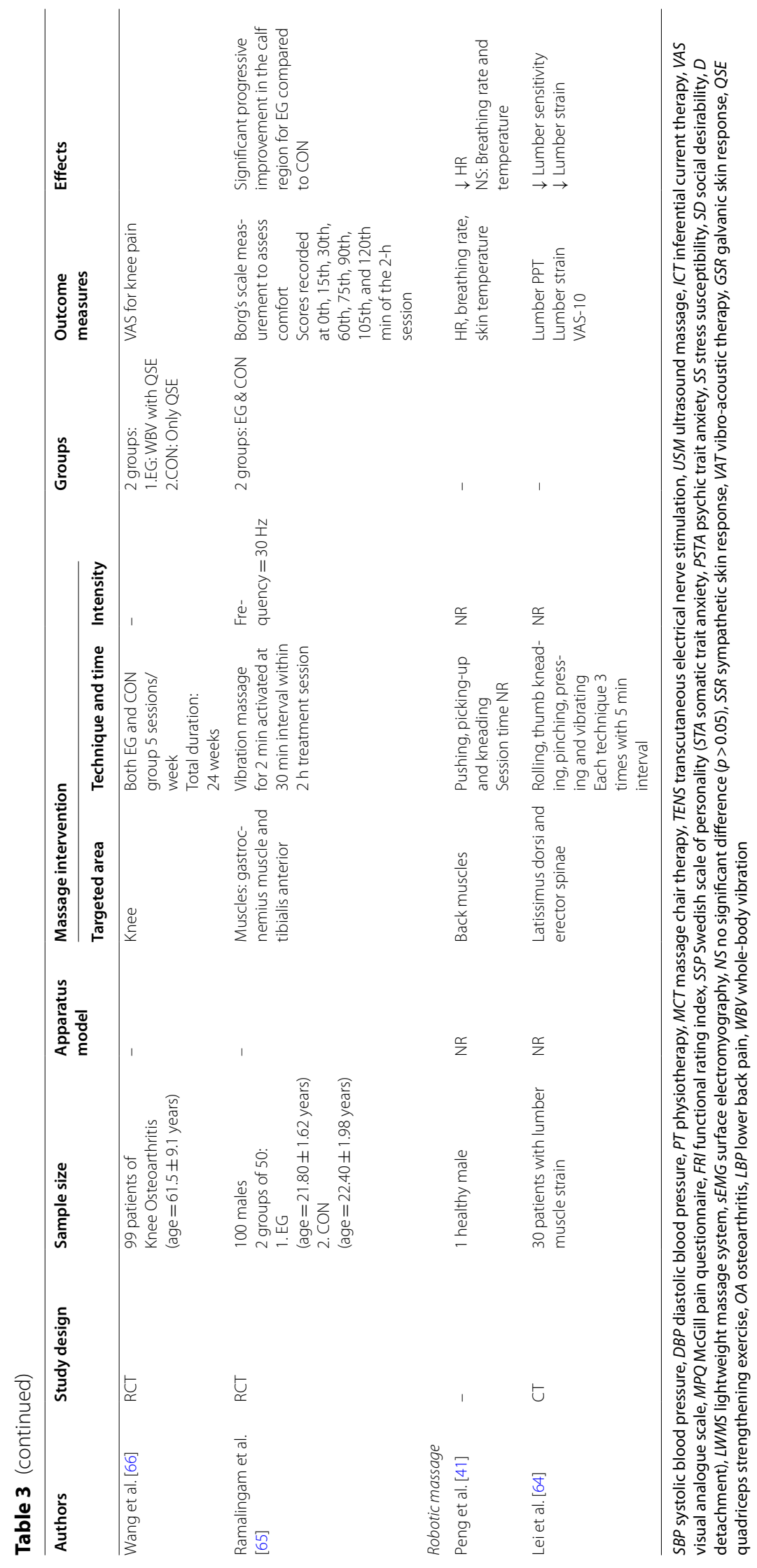


in interpreting the findings. Furthermore, in some studies, the use of footwear by subjects has not been reported. Another limitation indicated by Mahbub et al. [58] is on the knee flexion whilst the subject is placed on the vibration platform. As suggested by Brooke-Wavell and Mansfield [59], assuming an extended knee on the platform may cause deleterious effect on the spine and cervical joints because the vibration transverses toward the vertebral column. The International Society of Musculoskeletal and Neuronal Interactions (ISMNI) recommended listing parameters such as frequency/amplitude and acceleration level while describing the vibration involving exposure of subjects to WBV (Rauch et al. [57]). However, most studies have reported vaguely on the measures of vibrational amplitude. Additionally, the placement of a transducer, which is used for measurement of vibrational intensity, is not reported accurately in majority of the studies. This unfortunately creates discrepancy in the reported vibrational parameters and raises implication of replicating the studies in the future. Furthermore, the available research works involving human exposure to WBV did not consider or discuss the recommendations of the international standard and in most cases, the adoption of safety limits when exposed to WBV is not clearly reported. Another limitation is the lack of reporting in environmental condition by the reviewed studies. As mentioned by Mahbub et al. [58], vascular response to vibration massage can change in accordance with differences in room temperature and therefore should be informed.

\section{Effects on psycho-physiological variables}

Majority of studies involving automated massage modalities have focused on the finding impact of these modalities in treating pain, discomfort, stress, and relaxation. The nature of outcomes measured in these studies is largely qualitative.

Kim et al. [22] studied the efficacy of mechanical massage chair therapy (MCT) in relieving chronic lower back pain. As compared to physiotherapy, the authors reported that MCT showed similar improvement in pain management where the result were based on a set of questionnaires. In a study by Lim et al. [27], the authors sought to find the effect of MCT with binaural beats by analyzing the electroencephalogram (EEG) and cognitive tests. Their study revealed a significant reduction in mental fatigue in patient as indicated by theta/beta as well as theta + alpha/beta indices in the treatment group for MCT combined with binaural beats. Moreover, there were significant improvement in cognition and memory for individuals who received MCT or MCT combined with binaural beats. Muller et al. [37, 38] and Willeke et al. [50] in three similar randomized controlled studies investigated if MCT and mental training could reduce stress and anxiety among office employees. Muller et al. in their initial study found a significant reduction in anxiety and stress susceptibility in groups which received MCT or MCT along with mental training. The results acquired from this study were largely based on questionnaires. Likewise, in their following study, Muller et al. measured the employee's heart rate, blood pressure and fingertip temperature. While they did not find any significant change in blood pressure and temperature, they reported that MCT combined with mental training induced reduction in heart rate over the course of the study. Surprisingly, in a very similar study by Willeke et al. [50] the authors could not find any significant change in heart rate variability (HRV). In contrast, they found a significant decrease in the blood cortisol levels in the MCT group. Furthermore, their study suggested a 
possible positive correlation of MCT with systolic blood pressure (SBP) and cortisol levels, and a negative correlation with HRV through a post hoc analysis. Another study by Lee et al. [25] on a relatively large number of subjects showed a decrease in the level of anxiety after MCT. However, their result being only from a single-subject measurement reduces its validity.

Franz et al. [68] explored the effects of a lightweight massage system (LWMS) integrated to a car seat on driver comfort and relaxation. Their experiment recounts reduced activity in trapezius muscle group, but no changes in rhomboideus muscle as measured with EMG. The authors relate such reduction in muscular activity as suggestive of decreased amount of stress due to mechanical massage.

Luo et al. [31] reported reduced delta and alpha power of electroencephalogram (EEG) frequency band after robotic hand massage. However, the evidence is weak as their study lacked a trial design and involved a very small sample size.

Two studies investigated the impact of mechanical bed massage on stress. While DoKim et al. [21] looked into physiological variables as HRV and EEG frequency band power, Lee et al. [26] also tracked changes in the biochemical markers of stress such as cortisol and norepinephrine. The study by Do-Kim et al. was a pre-test- and post-testbased trial design, contrary to Lee et al. who devised a treatment plan for 2 weeks and measured outcomes 2 weeks after the end of trial. Do-Kim et al. reported that automatic bed massage decreased HR and alpha-beta frequency power on EEG as well as improved scores on visual analogue scale (VAS) and state anxiety index (STAI). The study by Lee et al. had also showed a decrease in HRV, cortisol and norepinephrine levels, although the changes did not recur 2 weeks after the end of study for all parameters except for the norepinephrine level. Yang et al. [67] Wang et al. [66] and Ramalingam et al. [65] investigated the use of local vibration massage on pain management. The results were derived from questionnaires exhibited gradual improvement of pain perception throughout the study period.

In a recent review by Kerautret et al. [55] the authors discussed on the possibility of entirely autonomous massage modalities with ability to conciliate for both proactive and retroactive mode of motor control for user's massage experience. Earlier studies have largely involved highly technical and expensive robotic massage which may not be commercially feasible. However, in recent times there has been development of multiple automated massage modalities with added advantages of precision, availability, privacy and user choice. For instance, the iYU ${ }^{\circledR}$ Pro from Capsix Robotics, which started development in 2016, has complete autonomy and with aid of remote interface can switch from completely automated to user directed control for massage. However, further empirical evidence is required to conform to user safety and incurred benefits from such collaborative massage modalities. Safety is one of the prime issues, therefore, given the fact that with the freedom of use, the level of autonomy granted to massage robots can account for unwanted risk to users if pressure level or trajectories of massage and similar parameters are not adjusted prior to intervention, and subsequently monitored by attending professional. Lima et al. [63] have emphasized on the importance on the understanding of histological structure and physiological process to be accounted for during massage intervention. The issue is further complicated by the varying ergonomics of individuals in terms of muscle mass, personal preference in massage routine and 
possible presence of undiagnosed medical dysfunctionality. Therapeutic massage, hence, may never be complacent with only automated massage modalities and without involvement of the physiotherapist.

Automated massage modalities, from a preventive viewpoint may still be relevant when considering the importance of workload for physiotherapist and the limited medical resources available. Golovin et al. [61] suggest that such robotic massage modalities will provide an alternative means of assistance in cases when medical professionals are burdened with increased workload. In such cases these autonomous devices can administer simple massage techniques at a limited scale for preventive measures. Complex maneuvers such as stretching, strengthening and joint mobilization, which cannot be performed by robotic devices can be administer by a professional therapist, and thus providing compounding benefits. Hence, robotic massage can reduce risk of musculoskeletal injuries which occur from lack of joint mobilization and subsequently, improve well-being and health by allowing for regulated self-massage. It remains under scrutiny whether manual massage can be entirely substituted by its robotic counterpart. Even with the continuing advances in AI, it is questionable if physiotherapy can be robotized. Traditionally, manual massage therapy practice depends on feedback-based adjustment of manipulation of the patient's body by the therapist. The readjustment to ongoing feedback on the scar tissue ensures for treatment efficacy. Further studies on automated massage modalities are required and until then, mechanical apparatus such as massage chair and robots cannot be entirely integrated and therefore, remain another tool at the disposal of medical practitioners.

\section{Conclusion}

In this review of automated massage therapy, a range of massage modalities ranging from automated massage beds to robotic massage have been discussed pertaining to muscle properties, peripheral circulation and physio-psychological measures in different groups and health conditions. In many of these studies, a treatment or experimental group have been compared to a control group on basis of different types of psychological, physical, physiological and biochemical measures to evaluate massage effects. The studies have similarities and differences in terms of massage techniques involved such as kneading, rolling, and vibration. In almost all of these studies, massage has been shown to impart beneficial effects in both clinical and non-clinical experimental trials. It has been suggested that the beneficial effects incurred are induced from massage stimulation of pressure receptors on the body leading to enhanced vagal activity and reduced cortisol levels. However, in many cases, these effects are observed over a short period of time and/or involving small sample sizes. It is recommended that future studies look into the long-term effects of massage and design protocols conforming to international standards.

\footnotetext{
Abbreviations

TE: Trunk extension; SEM: Shear elastic modulus; CK: Creatine kinase; ROM: Range of motion; WASO-1: Waseda Asahi Oral-Rehabilitation Robot 1; RT: Randomized trial; CT: Clinical trial; CCT: Controlled clinical trial; RCT: Randomized control trial; VAS: Visual analogue scale; HRV: Heart rate variability; BME: Back muscle endurance; EG: Experimental group; CON: Control group; NS: No significant difference ( $p>0.05)$; EMG: Electromyogram; EEG: Electroencephalogram; STAI: State anxiety inventory; SAM: Self-assessment manakin; SM: Single massage group; CM: Massage + heating (combined massage) group; LA: Blood lactate concentration; IL-6: Interleukin 6 (cytokine); Mb: Myoglobin; MMP-2: Metalloproteinase 2;
} 
MIF: Maximal isometric force; LDH: Lactate dehydrogenase; NIRS: Near infrared spectroscopy; MVC: Maximal voluntary contraction; SBP: Systolic blood pressure; DBP: Diastolic blood pressure; PT: Physiotherapy; MCT: Massage chair therapy; TENS: Transcutaneous electrical nerve stimulation; USM: Ultrasound massage; ICT: Inferential current therapy; MPQ: McGill pain questionnaire; FRI: Functional rating index; SSP: Swedish scale of personality; STA: Somatic trait anxiety; PSTA: Psychic trait anxiety; SS: Stress susceptibility; SD: Social desirability; D: Detachment; LWMS: Lightweight massage system; SEMG: Surface electromyography; SSR: Sympathetic skin response; GSR: Galvanic skin response; QSE: Quadriceps strengthening exercise; OA: Osteoarthritis; LBP: Lower back pain; WBV: Whole-body vibration.

\section{Acknowledgements}

We would like to thank Ogawa Malaysia for providing the hardware required in these studies. We appreciate both assistant researchers William Chai Nam Aik and Phang Siau Boon from Universiti Malaya-Ogawa Malaysia Joint Research Project for their ideas and technical support. This work was supported by Joint Research Grant, Universiti Malaya_-Ogawa Malaysia, under Grants (PV051-2019 and PV052-2019).

\section{Authors information}

Ayan Paul is currently a Master by research student at Biomedical Engineering Department, Faculty of Engineering, Universiti Malaya. He obtained his bachelor's degree from the same university in 2019. His research interest is biomedical signal processing.

Dr. Juliana Usman is a Senior Lecturer from the Department of Biomedical Engineering, University of Malaya. She graduated with a Bachelor of Biomedical Engineering degree and a Master of Engineering Science from the University of Malaya. She received her doctorate degree from the University of New South Wales in 2012. Her area of interest is sports biomechanics specializing in injury prevention and performance enhancement.

Mohd Yazed Ahmad is a Senior Lecturer from the Department of Biomedical Engineering, University of Malaya. His research expertise include biomedical sensors, signal processing, and bioinstrumentation.

Hamidreza Mohafez received the B.A.Sc. degree from the K. N. Toosi University of Technology in 2001, the M.A.Sc. degree from Tarbiat Modares University, Tehran, Iran, in 2004, and the Ph.D. degree from Universiti Putra Malaysia, Kuala Lumpur, Malaysia, in 2016. He is currently a Senior Lecturer in biomedical engineering with the Department of Biomedical Engineering, Faculty of Engineering, Universiti Malaya, Kuala Lumpur, Malaysia. His research interests include statistical analysis, medical image analysis, medical imaging systems, machine learning, and artificial intelligence.

Hadizadeh Maryam received her Phd from Universiti Putra Malaysia. She is currently a senior lecturer at Centre for Sports and Exercise Sciences, University of Malaya. Her research areas are sports biomechanics, sport sciences and physiology.

Ong Zhi Chao received his Ph.D. from the University of Malaya, Malaysia. He is currently a Senior Lecturer at the Mechanical Engineering Department, Faculty of Engineering, University of Malaya. His research interests include vibration, modal analysis, impact-synchronous modal analysis (ISMA), structural \& rotor dynamics, virtual instrumentation, signal processing and fault diagnostic.

Khairunnisa Hasikin received the B.Eng. degree in electrical engineering and the M.Sc. Eng. degree in biomedical engineering from the University of Malaya, Malaysia, and the Ph.D. degree from Universiti Sains Malaysia. She is currently a Senior Lecturer with the Department of Biomedical Engineering, Faculty of Engineering, Universiti Malaya. Her research interests include medical image processing and analysis, expert systems, medical informatics and sustainability management.

Khin Wee Lai received his PhD from Technische Universitat Ilmenau, Germany and Universiti Teknologi Malaysia (UTM) under DAAD PhD Sandwich Programme. He is currently the Head Programme - Master of Engineering (Biomedical) at Faculty of Engineering, University Malaya. He is a Chartered Engineer registered under the Engineering Council, U.K. Engineers Australia, APEC Engineer, IntPE(Australia), and also a Professional Engineer registered under the Board of Engineers, Malaysia. He is a Fellow of Engineers Australia, and Fellow of the Institution of Engineers, Malaysia (IEM). His research interests include computer vision, machine learning, medical image processing and healthcare analytics.

\section{Authors' contributions}

All the authors contributed equally to data collection, processing, experiments and article writing. All authors read and approved the final manuscript

\section{Funding}

This work was supported by Joint Research Grant, Universiti Malaya_-Ogawa Malaysia, under Grants (PV051-2019 and PV052-2019).

\section{Availability of data and materials}

All the data are available upon request from the corresponding author,

\section{Declarations}

Ethics approval and consent to participate

Not applicable. All the database was obtained from the literature that are publicly available.

\section{Consent for publication}

Not applicable.

\section{Competing interests}

There is no conflict of interest reported by any authors. 


\begin{abstract}
Author details
${ }^{1}$ Department of Biomedical Engineering, Universiti Malaya, 50603 Kuala Lumpur, Malaysia. ${ }^{2}$ Centre for Sport and Exercise Sciences, Universiti Malaya, Jalan Universiti, 50603 Kuala Lumpur, Malaysia. ${ }^{3}$ Department of Mechanical Engineering, Universiti Malaya, 50603 Kuala Lumpur, Malaysia.
\end{abstract}

Received: 7 June 2021 Accepted: 31 August 2021

Published online: 15 September 2021

\title{
References
}

1. M. Aourell, M. Skoog, J. Carleson, Effects of Swedish massage on blood pressure. Complement. Ther. Clin. Pract. 11(4), 242-246 (2005). https://doi.org/10.1016/j.ctcp.2005.02.008

2. Y. Ariji, A. Katsumata, Y. Hiraiwa, M. Izumi, S. Sakuma, M. Shimizu, K. Kurita, E. Ariji, Masseter muscle sonographic features as indices for evaluating efficacy of massage treatment. Oral Surg. Oral Med. Oral Pathol. Oral Radiol. Endod. 110(4), 517-526 (2010). https://doi.org/10.1016/j.tripleo.2010.05.003

3. Y. Ariji, M. Nakayama, W. Nishiyama, N. Ogi, S. Sakuma, A. Katsumata, K. Kurita, E. Ariji, Potential clinical application of masseter and temporal muscle massage treatment using an oral rehabilitation robot in temporomandibular disorder patients with myofascial pain. Cranio 33(4), 256-262 (2015). https://doi.org/10.1179/2151090314Y.0000000030

4. L. Bazzichi, A combination therapy of massage and stretching increases parasympathetic nervous activity and improves joint mobility in patients affected by fibromyalgia. Health $\mathbf{0 2}$, 919-926 (2010). https://doi.org/10.4236/ health.2010.28136

5. V. Buttagat, W. Eungpinichpong, D. Kaber, U. Chatchawan, P. Arayawichanon, Acute effects of traditional Thai massage on electroencephalogram in patients with scapulocostal syndrome. Complement. Ther. Med. 20(4), 167-174 (2012). https://doi.org/10.1016/j.ctim.2012.02.002

6. D.C. Cherkin, D. Eisenberg, K.J. Sherman, W. Barlow, T.J. Kaptchuk, J. Street, R.A. Deyo, Randomized trial comparing traditional Chinese medical acupuncture, therapeutic massage, and self-care education for chronic low back pain Arch. Intern. Med. 161(8), 1081-1088 (2001). https://doi.org/10.1001/archinte.161.8.1081

7. M.A. Diego, T. Field, Moderate pressure massage elicits a parasympathetic nervous system response. Int. J. Neurosci. 119(5), 630-638 (2009). https://doi.org/10.1080/00207450802329605

8. M.A. Diego, T. Field, C. Sanders, M. Hernandez-Reif, Massage therapy of moderate and light pressure and vibrator effects on EEG and heart rate. Int. J. Neurosci. 114(1), 31-44 (2004). https://doi.org/10.1080/00207450490249446

9. J.L. Durkin, A. Harvey, R.L. Hughson, J.P. Callaghan, The effects of lumbar massage on muscle fatigue, muscle oxygenation, low back discomfort, and driver performance during prolonged driving. Ergonomics 49(1), 28-44 (2006). https://doi.org/10.1080/00140130500356882

10. L. Fang, J. Jiang, B. Zhang, Y. Wang, J. Zhang, Y. Cui, L. Ma, L. Hu, J. Zhang, A massage robot based on Chinese massage therapy. Ind. Robot Int. J. 40(2), 158-172 (2013). https://doi.org/10.1108/01439911311297775

11. T. Field, Massage therapy facilitates weight gain in preterm infants. Curr. Dir. Psychol. Sci. 10(2), 51-54 (2001). https:// doi.org/10.1111/1467-8721.00113

12. T. Field, M.A. Diego, M. Hernandez-Reif, O. Deeds, B. Figuereido, Moderate versus light pressure massage therapy leads to greater weight gain in preterm infants. Infant Behav. Dev. 29(4), 574-578 (2006). https://doi.org/10.1016/j. infbeh.2006.07.011

13. T. Field, C. Morrow, C. Valdeon, S. Larson, C. Kuhn, S. Schanberg, Massage reduces anxiety in child and adolescent psychiatric patients. J. Am. Acad. Child Adolesc. Psychiatry 31(1), 125-131 (1992). https://doi.org/10.1097/00004583199201000-00019

14. K.E. Games, J.M. Sefton, Whole-body vibration influences lower extremity circulatory and neurological function. Scand. J. Med. Sci. Sports 23(4), 516-523 (2013). https://doi.org/10.1111/j.1600-0838.2011.01419.x

15. T. Hatayama, S. Kitamura, C. Tamura, M. Nagano, K. Ohnuki, The facial massage reduced anxiety and negative mood status, and increased sympathetic nervous activity. Biomed. Res. (Tokyo, Japan) 29(6), 317-320 (2008). https://doi. org/10.2220/biomedres.29.317

16. M. Hernandez-Reif, T. Field, J. Krasnegor, Z. Hossain, H. Theakston, I. Burman, High blood pressure and associated symptoms were reduced by massage therapy. J. Bodyw. Mov. Ther. 4(1), 31-38 (2000). https://doi.org/10.1054/jbmt. 1999.0129

17. A.J. Herrero, J. Martín, T. Martín, D. García-López, N. Garatachea, B. Jiménez, P.J. Marín, Whole-body vibration alters blood flow velocity and neuromuscular activity in Friedreich's ataxia. Clin. Physiol. Funct. Imaging 31(2), 139-144 (2011). https://doi.org/10.1111/j.1475-097X.2010.00992.x

18. Y. Hiraiwa, Y. Ariji, Y. Kise, S. Sakuma, K. Kurita, E. Ariji, Efficacy of massage treatment technique in masseter muscle hardness: robotic experimental approach. Cranio 31(4), 291-299 (2013). https://doi.org/10.1179/crn.2013.31.4.007

19. S. Imtiyaz, Z. Veqar, M.Y. Shareef, To compare the effect of vibration therapy and massage in prevention of delayed onset muscle soreness (DOMS). J. Clin. Diagn. Res. JCDR 8(1), 133-136 (2014). https://doi.org/10.7860/JCDR/2014/ 7294.3971

20. H. Ishii, H. Koga, Y. Obokawa, J. Solis, A. Takanishi, A. Katsumata, Development and experimental evaluation of oral rehabilitation robot that provides maxillofacial massage to patients with oral disorders. Int. J. Robot. Res. 28(9), 1228-1239 (2009). https://doi.org/10.1177/0278364909104295

21. D.-W. Kim, D.W. Lee, J. Schreiber, C.-H. Im, H. Kim, Integrative evaluation of automated massage combined with thermotherapy: physical, physiological, and psychological viewpoints. BioMed Res. Int. 2016, 2826905 (2016). https:// doi.org/10.1155/2016/2826905

22. S.-K. Kim, A. Min, C. Jeon, T. Kim, S. Cho, S.-C. Lee, C.-K. Lee, Clinical outcomes and cost-effectiveness of massage chair therapy versus basic physiotherapy in lower back pain patients: a randomized controlled trial. Medicine 99(12) e19514-e19514 (2020). https://doi.org/10.1097/MD.0000000000019514 
23. H. Koga, Y. Usuda, M. Matsuno, Y. Ogura, H. Ishii, J. Solis, A. Takanishi, A. Katsumata, Development of the oral rehabilitation robot WAO-1, in 2008 2nd IEEE RAS \& EMBS International Conference on Biomedical Robotics and Biomechatronics (2008), pp. 556-561. https://doi.org/10.1109/BIOROB.2008.4762801

24. H. Kunikata, K. Watanabe, M. Miyoshi, T. Tanioka, The effects measurement of hand massage by the autonomic activity and psychological indicators. J. Med. Investig. JMI 59(1-2), 206-212 (2012). https://doi.org/10.2152/jmi.59.206

25. S.A. Lee, C.L. Murphy, V.M. Taylor, Psychological experiences associated with robotic chair massage: a pilot study. Psychol. Stud. 62(2), 196-199 (2017). https://doi.org/10.1007/s12646-017-0404-z

26. Y.-H. Lee, B.N.R. Park, S.H. Kim, The effects of heat and massage application on autonomic nervous system. Yonsei Med. J. 52(6), 982-989 (2011). https://doi.org/10.3349/ymj.2011.52.6.982

27. J.-H. Lim, H. Kim, C. Jeon, S. Cho, The effects on mental fatigue and the cognitive function of mechanical massage and binaural beats (brain massage) provided by massage chairs. Complement. Ther. Clin. Pract. 32, 32-38 (2018). https://doi.org/10.1016/j.ctcp.2018.04.008

28. E.B. Lohman 3rd., G.S. Bains, T. Lohman, M. DeLeon, J.S. Petrofsky, A comparison of the effect of a variety of thermal and vibratory modalities on skin temperature and blood flow in healthy volunteers. Med. Sci. Monit. Int. Med. J. Exp. Clin. Res. 17(9), MT72-MT81 (2011)

29. E.B. Lohman, K.S.B. Sackiriyas, G.S. Bains, G. Calandra, C. Lobo, D. Nakhro, G. Malthankar, S. Paul, A comparison of whole body vibration and moist heat on lower extremity skin temperature and skin blood flow in healthy older individuals. Med. Sci. Monit. Int. Med. J. Exp. Clin. Res. 18(7), CR415-CR424 (2012). https://doi.org/10.12659/msm. 883209

30. R.C. Luo, C.C. Chang, Electromyographic evaluation of therapeutic massage effect using multi-finger robot hand. IEEE Int. Conf. Robot. Autom. 2011, 2431-2436 (2011). https://doi.org/10.1109/ICRA.2011.5980147

31. R.C. Luo, C. Hsu, S. Chen, Electroencephalogram signal analysis as basis for effective evaluation of robotic therapeutic massage, in IEEE/RSJ International Conference on Intelligent Robots and Systems (IROS), vol. 2016 (2016), pp. 2940-2945. https://doi.org/10.1109/IROS.2016.7759455

32. N. Manimmanakorn, A. Manimmanakorn, W. Phuttharak, M.J. Hamlin, Effects of whole body vibration on glycemic indices and peripheral blood flow in type II diabetic patients. Malays. J. Med. Sci. MJMS 24(4), 55-63 (2017). https:// doi.org/10.21315/mjms2017.24.4.7

33. H. Menéndez, J. Martín-Hernández, C. Ferrero, A. Figueroa, A.J. Herrero, P.J. Marín, Influence of isolated or simultaneous application of electromyostimulation and vibration on leg blood flow. Eur. J. Appl. Physiol. 115(8), 1747-1755 (2015). https://doi.org/10.1007/s00421-015-3161-5

34. U.H. Mitchell, S.C. Hilton, E. Hunsaker, J. Ulfberg, Decreased symptoms without augmented skin blood flow in subjects with RLS/WED after vibration treatment. J. Clin. Sleep Med. JCSM Off. Publ. Am. Acad. Sleep Med. 12(7), 947-952 (2016). https://doi.org/10.5664/jcsm.5920

35. H. Mori, H. Ohsawa, T.H. Tanaka, E. Taniwaki, G. Leisman, K. Nishijo, Effect of massage on blood flow and muscle fatigue following isometric lumbar exercise. Med. Sci. Monit. Int. Med. J. Exp. Clin. Res. 10(5), CR173-CR178 (2004)

36. C.A. Moyer, J. Rounds, J.W. Hannum, A meta-analysis of massage therapy research. Psychol. Bull. 130(1), 3-18 (2004). https://doi.org/10.1037/0033-2909.130.1.3

37. J. Muller, A. Ekström, M. Harlén, U. Lindmark, L. Handlin, Mechanical massage and mental training programs effect employees' heart rate, blood pressure and fingertip temperature-an exploratory pilot study. Eur. J. Integr. Med. 8(5), 762-768 (2016). https://doi.org/10.1016/j.eujim.2016.06.002

38. J. Muller, L. Handlin, M. Harlén, U. Lindmark, A. Ekström, Mechanical massage and mental training programmes affect employees' anxiety, stress susceptibility and detachment-a randomised explorative pilot study. BMC Complement. Altern. Med. 15, 302 (2015). https://doi.org/10.1186/s12906-015-0753-x

39. J.J. Newham, M. Westwood, J.D. Aplin, A. Wittkowski, State-trait anxiety inventory (STAI) scores during pregnancy following intervention with complementary therapies. J. Affect. Disord. 142(1), 22-30 (2012). https://doi. org/10.1016/j.jad.2012.04.027

40. Y. Obokawa, J. Solis, H. Ishii, H. Koga, A. Takanishi, A. Katsumata, Clinical massage therapy with the oral-rehabilitation robot in patients with temporomandibular joint disorders, in 2009 9th International Conference on Information Technology and Applications in Biomedicine (2009), pp. 1-4. https://doi.org/10.1 109/ITAB.2009.5394420

41. C.-C. Peng, T.-S. Hwang, C.-J. Lin, Y.-T. Wu, C.-Y. Chang, J.-B. Huang, Development of intelligent massage manipulator and reconstruction of massage process path using image processing technique, in 2010 IEEE Conference on Robotics, Automation and Mechatronics (2010), pp. 551-556. https://doi.org/10.1109/RAMECH.2010.5513135

42. R.V.V. Petrescu, R. Aversa, A. Apicella, F.I.T. Petrescu, Future Medicine services robotics. Am. J. Eng. Appl. Sci. (2016). https://doi.org/10.3844/ajeassp.2016.1062.1087

43. W. Poppendieck, M. Wegmann, A. Ferrauti, M. Kellmann, M. Pfeiffer, T. Meyer, Massage and performance recovery: a meta-analytical review. Sports Med. (Auckland, N.Z.) 46(2), 183-204 (2016). https://doi.org/10.1007/ s40279-015-0420-x

44. H. Pournot, J. Tindel, R. Testa, L. Mathevon, T. Lapole, The acute effect of local vibration as a recovery modality from exercise-induced increased muscle stiffness. J. Sports Sci. Med. 15(1), 142-147 (2016)

45. D. Robbins, P. Yoganathan, M. Goss-Sampson, The influence of whole body vibration on the central and peripheral cardiovascular system. Clin. Physiol. Funct. Imaging 34(5), 364-369 (2014). https://doi.org/10.1111/cpf. 12103

46. J. Solis, Y. Obokawa, H. Ishii, H. Koga, A. Takanishi, A. Katsumata, Development of oral rehabilitation robot WAO$1 R$ designed to provide various massage techniques, in IEEE International Conference on Rehabilitation Robotics, vol 2009 (2009), pp. 457-462. https://doi.org/10.1109//CORR.2009.5209562

47. A. Sonza, C.C. Robinson, M. Achaval, M.A. Zaro, Whole body vibration at different exposure frequencies: infrared thermography and physiological effects. Sci. World J. 2015, 452657 (2015). https://doi.org/10.1155/2015/452657

48. F. Taspinar, U.B. Aslan, N. Sabir, U. Cavlak, Implementation of matrix rhythm therapy and conventional massage in young females and comparison of their acute effects on circulation. J. Altern. Complement. Med. (New York, N.Y.) 19(10), 826-832 (2013). https://doi.org/10.1089/acm.2012.0932 
49. O. Tochikubo, S. Ri, N. Kura, Effects of pulse-synchronized massage with air cuffs on peripheral blood flow and autonomic nervous system. Circ. J. Off. J. Jpn. Circ. Soc. 70(9), 1159-1163 (2006). https://doi.org/10.1253/circj.70. 1159

50. W. Van Dijk, A.C. Huizink, J. Müller, K. Uvnäs-Moberg, A. Ekström-Bergström, L. Handlin, The effect of mechanical massage and mental training on heart rate variability and cortisol in Swedish employees - a randomized explorative pilot study. Front. Public Health 8, 82 (2020). https://doi.org/10.3389/fpubh.2020.00082

51. H. Walach, C. Güthlin, M. König, Efficacy of massage therapy in chronic pain: a pragmatic randomized trial. J. Altern. Complement. Med. (New York, N.Y.) 9(6), 837-846 (2003). https://doi.org/10.1089/107555303771952181

52. H. Zhong, W. Eungpinichpong, X. Wang, U. Chatchawan, S. Wanpen, O. Buranruk, Effects of mechanical-bed massage on exercise-induced back fatigue in athletes. J. Phys. Ther. Sci. 30(3), 365-372 (2018). https://doi.org/10.1589/jpts.30. 365

53. D.F. Zullino, S. Krenz, E. Frésard, E. Cancela, Y. Khazaal, Local back massage with an automated massage chair: general muscle and psychophysiologic relaxing properties. J. Altern. Complement. Med. 11(6), 1103-1106 (2005). https:// doi.org/10.1089/acm.2005.11.1103

54. P. Weerapong, P.A. Hume, G.S. Kolt, The Mechanisms of Massage and Effects on Performance Muscle Recovery and Injury Prevention. Sports Med. 35(3), 235-256 (2012). https://doi.org/10.2165/00007256-200535030-00004

55. Y. Kerautret, F. Di Rienzo, C. Eyssautier, A. Guillot, Selective effects of manual massage and foam rolling on perceived recovery and performance: Current knowledge and future directions toward robotic massages. Front. Physiol. 2020. https://doi.org/10.3389/fphys.2020.598898

56. A. Tyka, T. Pałka, A. Piotrowska, D. Żiżka, W. Pilch, A. Cebula, A. Tyka, The effect of vibro-massage on the level of selected marker of muscle damage and connective tissues after long-term physical esercise in males. J. Kinesiol. Exerc. Sci. 28(82), 21-27 (2018). https://doi.org/10.5604/01.3001.0013.5088

57. R. Frank, S. Harri, B. Steven, C. Marco, D. Hans, F. Dieter, R. Johannes, S. Eckhard, V. Sabine, R. Jörn, Reporting wholebody vibration intervention studies: Recommendations of the International Society of Musculoskeletal and Neuronal Interactions. J. Musculoskeletal Neur. Interact. 10, 193-198 (2010)

58. M.H. Mahbub, K. Hiroshige, N. Yamaguchi, R. Hase, N. Harada, T. Tanabe, A systematic review of studies investigating the effects of controlled whole-body vibration intervention on peripheral circulation. Clin. Physiol. Funct. Imaging 39(6), 363-377 (2019). https://doi.org/10.1111/cpf.12589

59. K. Brooke-Wavell, N.J. Mansfield, Risks and benefits of whole body vibration training in older people. Age. Ageing 38(3), 254-255 (2008). https://doi.org/10.1093/ageing/afp036

60. Y. Ariji, A. Katsumata, N. Ogi, M. Izumi, S. Sakuma, Y. lida, Y. Hiraiwa, K. Kurita, C. Igarashi, K. Kobayashi, H. Ishii, A. Takanishi, E. Ariji, An oral rehabilitation robot for massaging the masseter and temporal muscles: a preliminary report. Oral Radiol. 25(1), 53-59 (2009). https://doi.org/10.1007/s11282-009-0014-0

61. V. Golovin, A. Samorukov, M. Arkhipov, L. Kocherevskaya, Robotic Restorative Massage to Increase Working Capacity. Alter. Integr. Med. (2018). https://doi.org/10.4172/2327-5162.1000261

62. T.M. Marteau, H. Bekker, The development of a six-item short-form of the state scale of the Spielberger State-Trait Anxiety Inventory (STAI). Brit. J. Clin. Psychol. 31(3), 301-306 (1992). https://doi.org/10.1111/j.2044-8260.1992.tb009 97.x

63. C.R. Lima, D.F. Martins, W.R. Reed, Physiological Responses Induced by Manual Therapy in Animal Models: A Scoping Review. Front. Neurosci. (2020). https://doi.org/10.3389/fnins.2020.00430

64. L. Hu, Y. Wang, J. Zhang, J. Zhang, Y. Cui, L. Ma, J. Jiang, L. Fang, B. Zhang, A massage robot based on Chinese massage therapy. Indus. Robot: Int J. 40(2), 158-172 (2013). https://doi.org/10.1108/01439911311297775

65. K.S. Ramalingam, K. Karuppiah, S.D. Ramaiya, V. How, E.K. Perimal, H. Sadeghi Naeini, S. Sambasivam, K.C. Mani, Calf massager: Intervention for body muscle discomfort during prolonged standing. Human Factors. Ergon Manufact. Service Indus. 29(5), 426-434 (2019). https://doi.org/10.1002/hfm.20805

66. P. Wang, L. Yang, C. Liu, X. Wei, X. Yang, Y. Zhou, H. Jiang, Z. Lei, J.D. Reinhardt, C. He, Effects of Whole Body Vibration Exercise associated with Quadriceps Resistance Exercise on functioning and quality of life in patients with knee osteoarthritis: a randomized controlled trial. Clin. Rehab. 30(11), 1074-1087 (2016). https://doi.org/10.1177/02692 15515607970

67. J. Yang, D. Seo, The effects of whole body vibration on static balance spinal curvature pain and disability of patients with low back pain. J. Phys. Ther. Sci. 27(3), 805-808 (2015). https://doi.org/10.1589/jpts.27.805

68. M. Franz, R. Zenk, P. Vink, S. Hallbeck, The Effect of a Lightweight Massage System in a Car Seat on Comfort and Electromyogram. J. Manipulat. Physiol. Theraeutics 34(2), 107-113 (2011). https://doi.org/10.1016/j.jmpt.2010.12.002

\section{Publisher's Note}

Springer Nature remains neutral with regard to jurisdictional claims in published maps and institutional affiliations. 